\title{
Building World Class Universities in Yemen: Exploring Yemeni Higher Education Expert's Perceptions and Thoughts
}

\author{
Basheer Al-haimi, Daing Nasir Ibrahim, Ab Hamid MR
}

\begin{abstract}
World Class Universities (WCU) have substantially grown in popularity over the past couple of decades. These entities have incentivized the use of research as a tool for economic growth, as the emphasis on education and research development has led the governments to include them as key aspects for their national economic strategies. However, in a country like Yemen, there is a gap in research and development when it comes to the enhancement of the education system and university academia. Thus, this paper aims to investigate the requirements, initiatives and suitable strategic approaches that are required in order to create WCUs in Yemen. This is done by collecting and assessing the perceptions of Yemeni higher education experts. In order to achieve this goal, a qualitative method has been utilized for the research methodology, with the data being collected using deep interview systems. The selected population for the interview are five experts in the relevant field. The results of the study indicate that there are several requirements, initiatives and strategic approaches that can be executed in order for a WCU to be created in Yemen. Consequently, the expectation is for the findings of this research to provide a basis and bedrock for further initiative and proposals that can be used to guide policy makers in Yemen on developing the higher education institutes to a level which can compete with other countries around the world.
\end{abstract}

Index Terms: World Class Universities, Strategic approach, Requirements, Initiatives, Yemen

\section{INTRODUCTION}

Higher education institutions play major role tolerating a deepmoral responsibility to increase the awareness, knowledge, skills, and standardsrequired to create a just and sustainable future(Cortese, 2003).Noticeably, most of the advanced and developed countries' economic strength rely on knowledge economy that is induced by the production and transmission of information and knowledge(Powell \& Snellman, 2004). In producing such globally relevant knowledge, universities and specially the research institutions ones or what-so-called world-class universities play an immense and vital role in this (Roberts, 2009).Realizing the significance of such universities and their roles in increasing the knowledge economy, many

Revised Manuscript Received on September 22, 2019

Basheer Al-haimi, Faculty of Industrial Management, Universiti Malaysia Pahang, basheerump@gmail.com

Daing Nasir Ibrahim, Faculty of Industrial Management, Universiti Malaysia Pahang, daing@ump.edu.my

Ab Hamid MR, Faculty of Industrial Management, Universiti Malaysia Pahang, rashid@ump.edu.my developed and developing countriesstrive to build world-class universities (Wang, Wang, \& Liu, 2011). Therefore, it is an important for any country desires to bring prosper to its citizen and strive for sustainable and economic growth to build at least one world-class university.(Marginson, Kaur, \& Sawir, 2011) believes that no country can afford to do without one in the current century that depend most on knowledge economy.

Consequently, Yemen is one of the developing countries which is not rely on physical laboror natural resource comparing to its neighbors in the region. Therefore, researcher in this article view that there is a dire need to build at least one world-class university if not more. To achieve that, this study investigates and seeks to understand how we can build world-class universities in Yemen based on the views of the interviewed Yemen higher education experts.

\section{Research Questions}

The research questions guiding this study are:

1. What are the initiatives/ requirements needed to build world-class universities in Yemen?

2. What strategic approach is suitable to build world-class university in Yemen?

\section{LITERATURE REVIEW}

\section{A. The concept of World Class Universities}

Higher education institutes such as universities, have always been considered universal entities around the world, and as time progresses, their popularity has made them more accessible and international. This international field has created a competitive environment in which the universities strive to achieve the rank of World Class University. This, in of itself, has become a major driving factor of many educational establishments around the world (Sharpe, 2014).World Class University or WCUs, is a term that is mainly used by global research universities or flagship universities, which are backed up by governmental and institutional policies which incentivizes them to become more competitive, as to increase the national standing. However, this concept is not well defined, and has always been mentioned in an abstract or ambiguous way which could have multiple interpretations (Ahmed). 


\section{Building World Class Universities in Yemen: Exploring Yemeni Higher Education Expert's Perceptions and}

Thoughts

There is an earlier observasion that indicated WCU as an entity that: "everyone wants one, no one knows what it is, and no one knows how to get one" (Philip Albach, 2004).

During the last decade, the title of WCU has been used by the research universities to define institutes that are at the pinnacle of the higher education hierarchy (Salmi 2011). Thus, using this interpretation as context, the WCU can be defined with a multitude of ways. Some of which are listed as following, in a chronological order.

One the earlier scholars in the year 2001, suggested that if a university is not international in its environment and academia, then it is not eligible to be called a world class university (Wang, y, 2001). Decade later, a group of researchers focused on the national value of the university as a factor to define a world class university (Salmi, et al, 2011). Meaning that if there is no incentive that would encourage the growth and development of a nations degree of competitiveness, then it cannot really be called a WCU. However, it was also suggested that university ranking institutes and tables can be used as a metric for whether or not a university is world class. Some of these ranking tables includes, the Academic Ranking of World Universities (ARWU), the Times Higher Education World University Ranking, and the QS World University Rankings. Eventhough each of these metrics are different from one another, there is still a general pattern that indicates factors such as quality of education, internalization, research output, and presage and impact are key features for a WCU to have (Salmi, 2009).Later on, in 2012, WCUs were defined as prestigious institutes and universities, with their existence being a fundamental part of a nation's growth, and competitiveness in the global knowledge economy (Qi Wang. et al, 2012).

However, there is still suggestions from researchers that indicate that the term is ambiguous and the definition is not set (Li, 2012). Which according the definitions that is listed so far, each can be interpreted in its own way. With the researcher also recommending a definition which is also as ambiguous, such as defining the WCU as an institute that is different from the other existing institutes of its category. Particularly it should have features such as such as a highly qualified faculty, excellence in research, quality teaching, high levels of government and non-government sources of funding, international and highly talented students, academic freedom, well-defined autonomous governance structures; and well-equipped facilities for teaching, research, administration, and, student life.

In 2015, the latest definition mentioned earlier was elaborated in which the focus changed from nations contribution to where does the university fall in the academic hierarchy. This, has to be accomplished by also having the aim of the academic institute to focus on the creation of knowledge, as well as spreading it, all the while having the ability to educate a highly skilled workforce that is both technological in capabilities, and intellectual in deliver (Altbach, 2015).

The critical success factors for the WCUs seem to be focused around the concept of excellence in all areas of the university. As well as being involve in the most advanced and recent research. All the while, providing the researchers with freedom to research on all topics. This is required to be achieved with open borders, meaning a broad overview on how research not only benefits the nation it is residing in, but rather how interconnectivity with other universities can lead to common benefits and accomplishments ( $\mathrm{Li}$, Whalley et al. 2011).

\section{B. Existing Models/Approaches for Building World Class Universities}

According to (Yingjie 2001) "Building World-class universities became a national movement and many resources are invested into it " and "the fact of building world class university is not something to be fixed over nights". Thus, this level of importance, make it essential to be able to define the characteristics of a WCU, so that it can be used a building strategy for other institutes to follow.

There are general two aspects to developing a WCU. The first is the degree of support and resources that can be provided by the resident government. The second is how the university itself can turn into a WCU, and what steps and measures are required to be taken (Salmi, 2009). Thus, based on these perspectives, there are three possible models that can be followed in order to build a WCU. First is to upgrade an existing institution, second is merging existing institutions, and finally the third is creating new institutions. These three strategies are elaborated further in the following section.

\section{Upgrading existing institutions (Picking Winners)}

The first strategy in creating a WCU is to take an existing educational institution and upgrade it to a WCU. Although it is considered as one of the cheapest options, it is also one of the most difficult to implement (Salmi, 2009). This strategy was implement during the 1980's in china, however this strategy largely depends on the degree of support provided by the government, in which such behaviors has to be both encouraged and financed. An excellent example of such case would be Malaysia and Singapore. Both are culturally very similar as they existed under the Malaysian Kingdom and British Colonization.

\section{Merging existing institutions (hybrid formula)}

The second method is to merge existing institutions. Which many European nations such as France and Denmark have undertaken. France developed regional institutions by merging individual universities and institutes together In Denmark, a special kind of innovation funding was set up that would encourage this type of merger. China have also recently taken similar steps into merging Beijing Medical University into Beijing University in 2000, the merger of Shanghai Fudan University with a medical university, and the creation of Zhejiang University out of five regional universities (Salmi, 2009)

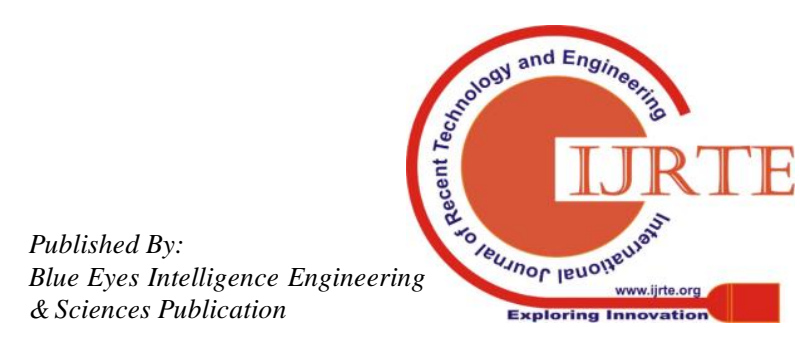




\section{Creating new institutions (Clean-slate approach)}

The final approach is to create new intuitions from the beginning with the goal of them becoming WCU. This approach is best applied to places where bureaucracy is a concern and can cause hindrance in the development or transformation of existing institutes. Typically, this type of WCU stem from the private sector, which is sometimes due to emerging businesses or former public universities being allowed to operate under looser regulations. Countries like Kazakhstan, aim on following this path and diversity their economy from natural resource based revenues like oil (Salmi, 2015). This strategy can also create a competitive environment for the existing pubic institutes in the nation, which would find incentive into increasing their standards in order to compete with the private universities.

\section{DATA COLLECTION AND METHODOLOGY}

In order to build a WCU in Yemen, the first step would be to identify the issues and conditions in which the Yemeni universities operate in. In order to achieve this goal, a qualitative method was employed which involve performing an in-depth interview with Yemeni higher education experts. The selected population for the interview are from higher and top level management that word in higher education. There are also experts that are particularly focused on education and higher education in Yemen, which can provide a useful insight into the inner working of the Yemeni institutes. Table 3.1 lists all the experts that participated in this study, alongside their positions, years of experience and the method in which they were interviewed. From the total of ten experts used, five were from top management, while the remaining are experts of the field. All of the interviews are performed either though phone, or face-to-face. The questions were designed to be open-ended so as to be able to guide the discussion towards a more informative pathway. This method of questions would allow the respondents to engage more in the discussion and share more information on the issues that could relate to the research. The interview was conducted and transcribed in both Arabic and English, whichever way that was more convenient for the interviewees. For interviews that were conducted in Arabic, a translation to English is performed. The total duration of the interview was 30 minutes, and it was recorded digitally.

Table 3.1: Demography of Interviewed People

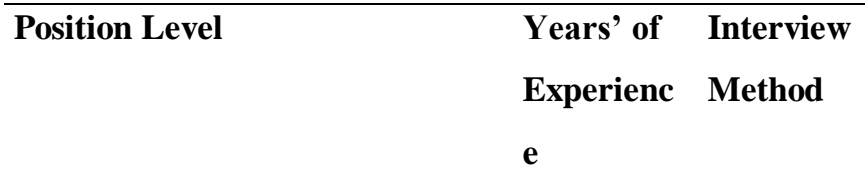

Minister of Higher Education 35 Years
$\begin{aligned} & \text { Face to } \\ & \text { Minister of Higher Education 40 Years } \\ & \text { face }\end{aligned}$
$\begin{aligned} & \text { Face to } \\ & \text { Deputy Minister of Higher }\end{aligned}$
face

Education 2001-2015

Minister of education 2003-2007 20 Years Phone
Dean of Postgraduate Studies 20 Years Phone -university RHODE Island and consultant to Deputy Minister Higher education Yemen

Vice Chancellor of University 20 Years Face to

Science and Technology -Yemen -1994-2007

Director of International Networking and Scholarships\& director of Islamic Body for Quality and Accreditation Currently

\section{DATA ANALYSIS}

Deductive and inductive approaches are employed to conduct the data analysis for this study. The main themes have been deductively derived from the research questions such as initiatives or requirements for building WCUs and strategic approaches. Moreover, several sub-themes are inductively generated from the expert's perceptions and thoughts on how to build WCUs in Yemen.

\section{FINDINGS AND DISCUSSION}

Based on the study conducted, and its results generated from the interviews with experts, there are several requirements, initiatives and proposed strategic approaches to build world-class universities in Yemen. These findings are described in the following themes.

\section{A. Theme 1:Initiatives/Requirements for Building WCUs in Yemen?}

In regards to the initiatives and requirements needed for building WCUs in Yemen, this study come out with several thoughts and opinions from the participants. These identified thoughts and opinions can be grouped into major sub-themes. These sub-themes are deeply discussed as follows:

\section{1) Develop vision and mission for the intended WCUs}

Due to it's significant to any strategic direction in any organization that lead to success(Tallant, 2009), many of the participants emphasized on this point more to be taken carefully and must start with this step. They suggested that , in order to build WCUs in Yemen, a vision, mission and ideas must should be developed first by focusing on the type of quality,experienced and capability management and leadership that should have future vision for the university and the country.

\section{2) Supportive of the top political leadership}

Political leadership or national leadership has a very significant role towards the success or failure of any government in any country. In addition, political leadership is very important to the economic development (Arndt, 1984).Hence, potential leaders can map the direction of the nations and organizations towards desired goal. In the journey of building world-class universities, many 
developed and developing governments have set up programs to achieve such desired goals. For instance, Hong Kong, Taiwan, China, Japan and Singapore have initiated different schemes in developing WCUs(Cheng, Wang, \& Liu, 2014).To support this statement, in the context of Yemen, a result of the interview in this study showed that the support of the top political leadership is a necessary step towards building WCUs in Yemen.

\section{3) Participation of private sector}

Some of the participants highlighted this point as one of the necessary requirement needed to build world-class universities in Yemen. They have reasoning that to the lack of the government financial resources which need more active role to be taken by private sectors. There are many forms of participation by private sectors and local industries. One of those forms is linkage and collaboration between universities and industries which is critical for skill development (Guimón, 2013). Moreover, collaboration can aid in the upgrade of infrastructure and grants for faculty members as well as providing access to new ideas and technologies.

\section{4) Benefits of other countries' experiences}

The interview participants believed that studying other successful experience of other countries is a good strategy where it will shorten the learning process and save time and cost. One of the interview participants said that "we have to study and get benefits of other countries' experience in developing WCUs, specially the countries that doesn't have much financial resources".

\section{5) Quality of university leadership}

In achieving world-class status, Jamil Salmi(Salmi, 2009) has introduced several characteristics and alignment factors which quality of university leadership is included. Therefore, to ensure the success of the universities and to achieve the higher education's goal of transformation, leadership with vision and having certain criteria is critical factor to be considered. According to one of the interview participants "In order to ensure the success of the intended WCUs, the selection of university top management should be based on competitive and choosing the best qualified leadership, and the vice chancellor should be questioned by the board of trustees about what he/she supposed to achieve". Hence, to support this statement, many countries that have world-class universities practices such strategies of selecting the best qualified leadership. For instance, one of the pivotal Malaysian institutional pillars in their strategic planning is leadership (Education, 2007).

\section{6) Selecting and preparing best teaching staff}

Teaching staff talent is one of the determinantsand characteristics for achieving world-class university status (Salmi, 2009). Talent or top-quality academic community is an important input element to ensure the success of any university. (Sharma, 2011) stated that "Global talent search is most powerful accelerating factor towards world-class university status whether they are in a poor or rich country, small or big (it is all about talent).In contrast what world-class university around the globe are doing, the interview participants in this study stated that "there is an open-policy in teaching staff selection, no development and evaluation for current teaching staff and there is no replacement and therefore, a center in the universities or ministry of higher education must be created that concerned with continues development of teaching staff".

\section{7) Focusing on specific fields}

According to some of the interview participants "Intended WCUs in Yemen have to focus and concentrate on specific fields and not all: engineering, technology and medicine are among such fields". In fact, up to date, there are 12 public universities in Yemen but the main and early established are Sana'a university, Aden niversity, Hodidah university, IBB university and Thamar university. These universities teach many fields and programs including, engineering, technology,humanities, social sciences, medicine and other fields. But anyhow, according the participant " these fields and programs need to be revaluated and decided which fields should remain and which one to be eliminated". Such reforms in the selection of the needed fields will lead the institution to use the public budget wisely and focusing more on the fields that are relevant to the countriesfor national economic development. In line with this result, the current WCUs are found not to have and offer all the academic programs and fields such as Caltech and LSE where they have small size in student's number and focusing on fields of engineering, technology and economics (Lee, 2013).

\section{8) Collaboration with WCUs around the world}

Collaboration or partnership is becoming an increasingly important factor for any organization's success and benefit (Network, 2018). It can give completive advantages, sharing resources and expertise that differ from one organization to another. Globally, higher education institutions are practicing such strategies and get the most advantages of it especially countries with limited resources (Altbach, 2009). In case of Yemen, where the country considered poor in enough resources to create WCUs, making the most alliances and networking locally and globally is cost saving strategy. Thereofre, interviwee in this study stated that "Signing Memorandum Of Understanding with world-class universities to participate in developing the idea and execute it as well as participating in doing the studies and researches".

\section{9) Self-finance resources}

Yemen universities budgets is heavily depends on the government funding which is considered very low compared to other universities in other countries whether in the region or outside (Basheer Al-haimi, 2018). For such reason, the interview participants recommended for seeking other self-financial resources. Interview participants suggested some self-resources that universities have to possess such as tuition fees, scientific researches, commercialized researches, consultations engineering commercialized consultations. 


\section{0) Admission policy}

In this point, all the interview participants emphasised to take this point into consideration as it's an important factor to achieve WCU status in Yemen. This is because attracting talent students are one of the key FEATURES of WCUs (Salmi, 2016). For instance, in building world-class universities in china, attracting and recruit top talent from home and overseas was one of their strategies (Ngok \& Guo, 2008). In contrast, the current practices in Yemen for admission policy is still an open policy. Therefore, one of requirements suggested the experts in this study is that "admission policy should be based on excellence and ability to pay".

\section{1) Autonomy of the universities}

A recent study conducted by (Basheer Al-haimi, 2018)revealed that "Yemen university autonomy is absent and Yemen universities do not have the freedom to make their own decisions in terms of self-governance, finance, administration as well as appointments". However, in this study, one of the critical requirements for building WCUs in Yemen suggested by the interviewee was the autonomy of the university financially and administratively. Therefore, the more ability of the university to govern itself is the more success and best performance is. Hence, many prestigious universities in the world enjoy full autonomous status(Lee, 2013).

\section{2) Activate the research and development}

To ensure success of any higher education institution, research and development is one of the most critical factor to be achieved.It plays a very important role in the success of any organization and especially the higher education institutions. Hence, the current global universities ranking companies put research and development at their heart of their criteria and methodologies. However, for the importance of the research and development and how it plays a critical role in enhancing the universities performance, interviewee in this study suggested to activate the research and development in Yemen higher education institutions. One of doing this is to open the postgraduate studies especially in engineering and technology fields and increase the number of postgraduate students

\section{B. Theme 2: Best Strategic Approaches for Building WCUs in Yemen?}

International experience showed three strategic approaches for building world-class universities namely: Building from scratch, Upgrading existing universities and emerged existing universities. Based on this, the researcher in this study explore the perception and opinion of the Yemeni higher education experts to select the best strategic approach that can effectively work in building world-class universities in Yemen. The opinions of the 5 experts are summarized in the following table 2.

Table 2:Respondents summary on best strategic approaches for building world-class universities in Yemen.

\section{No Strategies suggested by respondents}

1 Government should consider upgrading a small number of existing universities that have the potential for excelling.

2 Governments should encourage a number of existing institutions to merge and transform into a new university that would achieve the type of synergies corresponding to a world- class institutions.

3 Government could create new world class universities from scratch.

4 Re-divide Yemeni higher education into 4 Universities (one in the north, one in the south, one in the middle and one in the east) and link those universities with other world class universities in the world. Each university from the four mentioned should only have some faculties and not all.

5 Based on the current political and economic circumstances in the country, the best strategy is :

To qualify two universities, one is in the north and one is in the south. The two universities should be Sana'a and Aden and encourage them to be a research universities. The two universities should only focus on a set of required specializations. We focus on increasing the number of postgraduate studies. where the percentage should be $60 \%$ as postgraduate and $40 \%$ as undergraduate.

Based on the result shown above, it showed that most of the interview participants consensus to upgrade some existing universities and qualify them to become world-class universities. According to the interviewee that "due the financial constraints in Yemen, the best strategic approach for building world-class universities in Yemen is to upgrade two existing universities and due to the political situation these universities should be one in the north and one in the south".

\section{CONCLUSION}

On the other hand, this study come out with several initiatives, requirements and suggested strategies for building worlds-class universities in Yemen. Create ideas, visions and missions of the intended world-class universities, top political leaders support, private sectors support, selecting best academic staff and students, selecting universities leaders based on qualifications and potentials, self-financing, expand postgraduate studies programs and encourage research and development activities are among those initiatives and requirements suggested by the Yemeni higher education experts. Finally, the suggested most suitable strategic approach was upgrading two existing universities to become world-class universities.

\section{ACKNOWLEDGEMENT}

The researchers highly appreciate the efforts of the funder actors of this research. We greatly indebted to the Ministry of Higher Education Yemen and University Malaysia Pahang (UMP) for supporting this research.

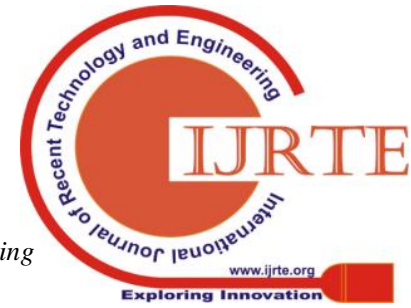


This work is partially supported by UMP under Grant No: PGRS180310

\section{REFERENCES}

[1] Ahmed, H. O. K. (2015). Strategic Approach for Developing World-Class Universities in Egypt. Journal of Education and Practice, 6(5), 125-145.

[2] Altbach, P. G. (2004). The costs and benefits of world-class universities. Academe, 90(1), 20

[3] Altbach, P. G. (2009). Peripheries and centers: Research universities in developing countries. Asia Pacific Education Review, 10(1), 15-27.

[4] Arndt, H. W. (1984). The role of political leadership in economic development. Canadian Journal of Development Studies/Revue canadienne d'études du développement, 5(1), 51-63.

[5] Basheer Al-haimi, A. H., Mr, Fadhl Hujainah. (2018). FACTORS AFFECTING YEMEN HIGHER EDUCATION INSTITUTIONS PERFORMANCE: CHALLENEGES \& OBSTACLES. International Journal of Engineering \& Technology, 7, 256-260.

[6] Cheng, Y., Wang, Q., \& Liu, N. C. (2014). How world-class universities affect global higher education How World-Class Universities Affect Global Higher Education (pp. 1-10): Springer.

[7] Cortese, A. D. (2003). The critical role of higher education in creating a sustainable future. Planning for higher education, 31(3), 15-22.

[8] Education, M. o. H. (2007). National higher education action plan 2007-2010: Author Putrajaya, Malaysia.

[9] Guimón, J. (2013). Promoting university-industry collaboration in developing countries. World Bank, 3.

[10] Lee, J. (2013). Creating world-class universities: Implications for developing countries. Prospects, 43(2), 233-249.

[11] Marginson, S., Kaur, S., \& Sawir, E. (2011). Higher education in the Asia-Pacific: Strategic responses to globalization (Vol. 36): Springer Science \& Business Media.

[12] Network, V. (2018). Importance of Strategic Partnerships. Retrieved from http://www.valuenetwork.biz/about-us/company-news/61-strategic-part nerships

[13] Ngok, K., \& Guo, W. (2008). The quest for world class universities in China: Critical reflections. Policy Futures in Education, 6(5), 545-557.

[14] Powell, W. W., \& Snellman, K. (2004). The knowledge economy. Annu. Rev. Sociol., 30, 199-220.

[15] Roberts, J. (2009). The global knowledge economy in question. Critical perspectives on international business, 5(4), 285-303.

[16] Salmi, J. (2009). The challenge of establishing world-class universities: World Bank Publications.

[17] Salmi, J. (2016). Excellence strategies and the creation of world-class universities Matching Visibility and Performance (pp. 15-48): Springer.

[18] Sharpe, R. (2014). WHAT IS A WORLD CLASS UNIVERSITY? A LITERATURE REVIEW. Retrieved from http://www.elementaleadership.co.uk/knowledgeportal/pdf/What $\% 20$ is $\% 20 \mathrm{a} \% 20$ World $\% 20$ Class\%20University.pdf

[19] Tallant, J. (2009). Importance of Vision, Mission, and Values in Strategic Direction.

[20] Wang, Q. H., Wang, Q., \& Liu, N. C. (2011). Building world-class universities in China: Shanghai Jiao Tong University. The road to academic excellence: The making of world-class research universities, 33-62.

[21] Robin Sharpe (2014). What is a World Class University ? A Literature review retrieved from the website http://www.elementaleadership.co.uk/knowledgeportal/pdf/What $\% 20$ is $\% 20 \mathrm{a} \% 20$ World\%20Class\%20University.pdf

[22] (Altbach, 2004; Salmi, 2009)

\section{AUTHORS PROFILE}

Basheer Al-haimi

Currently I am affiliated with Faculty of Industrial Management, Universiti Malaysia Pahang and my area of research is education.

Daing Nasir Ibrahim

I am Daing Nasir Ibrahim currently I am affiliated with Faculty of Industrial Management, Universiti Malaysia Pahang my area of research is education.

\section{Ab Hamid MR}

I am Ab Hamid currently I am affiliated with faculty of Industrial Management, Universiti Malaysia Pahang and my area of research is education. 